\title{
Nationale Komitees und internationale Organisationen
}

$\begin{array}{ll}\text { AJCC } & \begin{array}{l}\text { American Joint Committee on Cancer } \\ \text { BIJC }\end{array} \\ \text { CNC } & \begin{array}{l}\text { Canadian National TNM Committee } \\ \text { Comité Nacional Uruguayo TNM }\end{array} \\ \text { CNU-TNM } & \begin{array}{l}\text { Deutschsprachiges TNM-Komitee } \\ \text { DSK }\end{array} \\ \text { EORTC } & \begin{array}{l}\text { European Organization for Research on Treat- } \\ \text { ment of Cancer }\end{array} \\ \text { FIGO } & \begin{array}{l}\text { Fédération Internationale de Gynécologie et } \\ \text { d'Obstétrique }\end{array} \\ \text { FTNM } & \begin{array}{l}\text { French TNM Group } \\ \text { Italian Committee for TNM Cancer Classifica- } \\ \text { ICC }\end{array} \\ \text { tion } \\ \text { JJC } & \begin{array}{l}\text { Japanese Joint Committee } \\ \text { Société Internationale d'Oncologie Pédiatrique }\end{array}\end{array}$


